Max-Planck-Institut für demografische Forschung

Max Planck Institute for Demographic Research

Konrad-Zuse-Strasse 1 - D-18057 Rostock - GERMANY

$\mathrm{Tel}+49$ (0) 3812081 - 0; Fax +49 (0) 3812081 - 202;

http://www.demogr.mpg.de

MPIDR WORKING PAPER WP 2009-015

JUNE 2009

\title{
Downward Mobility, Unemployment and Mortality
}

Sunnee Billingsley (billingsley@demogr.mpg.de)

This working paper has been approved for release by: Vladimir Shkolnikov (shkolnikov@demogr.mpg.de), Head of the Laboratory of Demographic Data.

(C) Copyright is held by the authors.

Working papers of the Max Planck Institute for Demographic Research receive only limited review. Views or opinions expressed in working papers are attributable to the authors and do not necessarily reflect those of the Institute. 
Downward Mobility, Unemployment and Mortality

Sunnee Billingsley

Max Planck Institute for Demographic Research

Pompeu Fabra Universitat

Abstract:

This research offers fresh evidence 1) on the contribution of social mobility to health differentials by proposing a new link between downward mobility and health: downward mobility itself may have an immediate impact on health, above and beyond selection, origin or destination effects, and 2) on causes behind the mortality crisis in Russia by testing an innovative operationalization of the negative impact of economic crisis and transition. Specifically, downward mobility as well as unemployment are assessed in this study as possible contributors to increased risk of death from 19942005 in Russia. Using RLMS data and Cox proportional hazard models, the results demonstrate that men were at greater risk of mortality when they experienced downward mobility, relative to men who did not. Women's mortality did not appear to be linked to downward mobility. Both men's and women's risk of death substantially increased when experiencing unemployment, relative to low-mid grade workers and relative to non-participation in the labor market. Whereas the impact of downward mobility appears immediate and short-term, the impact of unemployment was longer term and not limited to the year in which unemployment occurred for men. All findings were robust to adjustment of other potentially important factors such as alcohol consumption and health status that preceded downward mobility or unemployment. This robustness suggests that selection effect alone may not be a sufficient explanation for a high risk of death.

Key Words:

Mortality, downward mobility, health selection, health behavior, health differential, Russia 


\section{Introduction}

Social mobility has been well analyzed in past health research and has been linked to the continuing and, at times, increasing health differential among classes (e.g., Dahl \& Kjaersgaard 1993; Claussen et al. 2005; Hart et al. 1998; Davey Smith et al. 1997; Hemmingsson \& Lundberg 2005; Nilsson et al. 2005; Power et al. 1996; Stern 1983). In this tradition of research, researchers have attempted to understand whether the health divide continues to exist simply because people are sorted into classes through mobility according to health or whether the environment that is characteristic of a class supports or inhibits health. Therefore, much attention has been given to whether mobile individuals reflect the health and longevity characteristics of the origin or of the destination class more. One important assumption in the debate over the health divide is that there is selectivity into mobility based on health; so those who are unhealthy are more likely to be downwardly mobile and vice versa. Another assumption reflects a cumulative life course perspective; prolonged exposure to a class environment is how class location and mobility matter to health.

While both of these assumptions are based on supporting evidence in the literature and are not being called into question, this paper proposes an altogether different interpretation of the impact of mobility. Rather than further assess the importance of selection into a class or exposure to the risks associated with a class, I propose that experiencing downward mobility may in and of itself be detrimental to health due to the stress experienced over the loss of previous resources and social status. In other words, this research focuses on whether there is a health reaction to this event, which is fundamentally different to how downward mobility has been considered to matter to health in past research. Siegrist (2000) outlines a theoretical framework for understanding how a threat to individuals' perceived core social roles, such as the work role, matter to health through inhibiting successful self-regulation, leading to "adaptive breakdown" and "addictive behaviors as a means of compensating for unsuccessful self-regulation” (p. 1286). As such, I argue that downward mobility has not received the space it deserves in research on health and longevity. Rather than perceive downward mobility as merely a recalibrating mechanism of the health divide, downward mobility may be a factor worth studying on its own, as it captures a critical life event that can be disorienting, devaluing and financially difficult for individuals.

With the recently increasing turbulence in the global market, we can expect increased job turnover and loss of jobs. Studying a case in which there has been high labor market turnover and economic instability off and on for a longer time period may provide the best opportunity to assess the importance of economic turbulence to health. This study, therefore, focuses on the case of Russia, in which radical changes have been taking place at the economic and social level since the end of the Soviet Union in 1991. During the transition from communism, market reform increased the importance of income through wage dispersion and price liberalization; moreover, economic restructuring and crisis increased the difficulty of making ends meet through inflation, wage arrears, and job loss (Blanchard 1997; Barr 2001). In other words, the transition from communism increased returns to being located in a higher class and having more resources at the same time that it knocked workers out of previous jobs and increased the cost of living. 
Moreover, Russia is a particularly interesting case to study the relationship between health and mobility because these economic, political and social transformations were accompanied by dramatic increases in mortality rates, particularly for working-aged men (Shkolnikov et al. 2001). The debate over the causes of the mortality crisis in Russia has been limited in its capacity to disentangle contributing factors at the individual level, in contrast to macro-level factors, as few resources exist that offer detailed information about personal conditions before death occurred. After over a decade of scholarship on the subject, the debate revolves around two co-existing explanations: ${ }^{1}$ Researchers have argued that 1 ) increased economic insecurity and hardship created psychosocial stress and led to poorer health and mortality (Cornia and Paniccia 1998; Shkolnikov et al. 1998; Leon \& Shkolnikov 1998; Vågero \& Kislitsyna 2005) and; 2) poor health behaviors inherited from lifestyles that were developed under the Soviet regime led to an increase in mortality (Cockerham 1999, 2000, 2006; Shkolnikov et al. 2004a). Alcohol consumption has particularly proven to be a major factor in the increased death rates; Leon et al. (2007) estimate that almost half of all deaths can be attributed to hazardous drinking for working-aged men in their study on Izhevsk. Other epidemiological studies that have established the relationship between alcohol and mortality are the Novosibirsk cohort study (Malyutina et al. 2002) and a case-control study of working-aged men in Udmurtia (Shkolnikov et al. 2004b).

The two explanations are not necessarily mutually exclusive; indeed, Brainerd and Cutler (2005), among others, found evidence that both stress and alcohol consumption contributed to higher mortality in men. However, difficulties in assessing the validity of the economic context and stress explanation at the micro level have restricted efforts at empirically confirming the stress hypothesis, although many researchers acknowledge its plausibility. One epidemiological study of the city of Taganrog (Vågero \& Kislitsyna 2005) found a strong relationship between poverty, both present and past, and heart symptoms for both men and women. But findings that support the stress hypothesis have been called into question because of the possibility of endogeneity in the relationship between health and performance in the labor market, as well as poor health behavior and economic circumstances (Shkolnikov et al. 2004a). The present research seeks to contribute to the discussion by attempting a new strategy to assess whether experiences related to economic crisis and transition, reflected in micro-level data, contributed to deaths in Russia over the time period 1994-2005, as well as by carefully addressing this issue of endogeneity.

Given the tension between increasing returns to resources and the widespread loss of resources, I propose using downward social mobility and unemployment as proxies for the individual negative consequences of economic transition and crisis during this critical juncture. Downward mobility and loss of job imply a loss of previous resources, which can include social standing, income, embeddedness in social networks and prestige (Erikson \& Goldthorpe 1992; Treiman 1977). This loss of resources likely had negative effects on well-being and was also likely accompanied by psychosocial stress for those, or their family members, who were not fortunate in the labor market; hence, this research will investigate whether downward mobility and unemployment impacted health. While downward mobility and unemployment likely

\footnotetext{
${ }^{1}$ See Stillman (2006) for an extensive review of explanations and research on mortality trends across the entire post-communist region.
} 
both increase stress due to loss of resources, the difference between the two may be one of degree. Therefore, we may expect unemployment to have a greater impact since overall loss of resources and increased uncertainty should be greater when experiencing unemployment. We may also expect a differential impact of downward mobility based on the level from which one drifts downward. These are empirical issues that will be addressed in the analysis.

The relationship between unemployment and mortality at the micro-level has been explored, particularly in relation to the post-communist transition and economic crisis (see Blazek and Dzúrová 2000 for Czech Republic; Cornia 2000 and Walberg et al. 1998 for Russia; Krumins and Usackis 2000 for Latvia; Riphan and Zimmerman 2000 for the former GDR; Abdala, Geldstein, and Mychaszula 2000 for Argentina). Strully (2009) recently investigated the link between unemployment and health by studying the impact of unemployment on workers who lost their jobs due to plant closure and not for health reasons, thus, avoiding the endogeneity problem often inherent in such research. She finds that with the closing of a firm, those who were laid off, and did not have a previous health condition, had $83 \%$ higher odds of developing a new health condition. The odds of experiencing fair or poor health increased by $54 \%$. Strully's research demonstrates not only an immediate health reaction to labor market turnover but that the experience of losing one's job also has lasting effects on health. In the case of Russia, and using the same data source as in this study, Denisova (2009) finds that experiencing poverty increases the risk of death for men and women of all ages in Russia. Although this finding has a different meaning than downward mobility, it does capture the impact of minimal resources, especially as an experience that is new.

To summarize, I argue that the economic crisis and transition brought about downward mobility and unemployment, which contributed to the mortality crisis. I use the Russian Longitudinal Monitoring Survey (RLMS), which allows for an analysis that distinguishes between factors related to economic crisis and transition and pre-existing health conditions and behavior. Specifically, I address the following questions: 1) What characteristics were related to an increased risk of death, especially in regards to resources? 2) Did experiencing downward mobility or unemployment increase the risk of death above and beyond individual characteristics and economic conditions? 3) If mobility or unemployment matter to health and longevity, is the nature of the risk immediate or prolonged? 4) Does excessive alcohol consumption or poor health preceding downward mobility or unemployment explain the increased risk of death? The next sections describe the data and analytical strategy as well as the results. I conclude with a discussion of the results, possible forms of bias in this study and further areas of research needed to illuminate the link between turbulent economic contexts and health.

\section{DATA AND METHODS}

The RLMS data used in this analysis cover the years 1994-2005 and relied on a multistage probability sampling of dwelling units from over 2000 raions (similar to counties). These raions cover $95.5 \%$ of the total population of Russia. Highly remote areas, as well as Chechnya, were not included in the sample. To allow for lower response rates in highly urbanized areas, each round of data collection oversampled accordingly, leading to a sample target of over 4700 dwellings a year. Around 4000 households were surveyed each year and the response rate varied from $50.8 \%$ in the 
most recent wave to $87.6 \%$ in the first. Within the household, the response rate was at least $97 \%$ in each round. Although this survey was not designed to be a true panel data set, it is possible to follow individuals over many waves. ${ }^{2}$ Therefore, this analysis includes individuals that participated in multiple survey rounds.

The independent variables that were included in all models were age, sex, urban area, type of household, union status, smoking status, excessive alcohol consumption, diagnoses of heart attack or stroke, missing work status, self-rated health, labor force status and class, and education level. Exposure and occurrence rates of all variables are provided in Appendix A. Age was introduced as a categorical variable in which respondents were either under the age of 40 , between $40-44,45-49,50-54,55-59$, or above the age of 60 . Disaggregating age between 40 and 60 will give a closer look at the age groups that are particularly interesting to study in Russia's mortality crisis. A categorical variable captures whether the respondent currently lives in an urban area, township or rural area. Type of household is a categorical variable in which households are identified according to their household head. The three categories in which a household may be classified are having a working-aged male in the household, a working-age female in the household or having only a retired male or female or a young head of the household who is not employed. Union status reflects whether the respondent is in a cohabiting union.

Smoking status is a dichotomous variable in which the respondent is coded as either being a current smoker or not. Excessive alcohol consumption is measured with a dichotomous variable indicating whether the respondent falls into the top decile of total grams of alcohol consumed daily. ${ }^{3}$ The construction of these deciles is genderspecific and is based only on those who drink alcohol so the amounts were not biased by those who do not drink. Therefore, the bottom $10 \%$ is inflated with the addition of all the non-drinkers. The mean number of grams of alcohol consumed by excessive drinkers who are women and men was 54 and 201, respectively. The respondents who reported high consumption levels most often consumed vodka and other hard liquor. A dummy variable is introduced into the model as well that indicates whether the respondent has drunk any alcohol at all in the last month in order to make a distinction between those who do not drink alcohol at all. The risk of death for non-drinkers is expected to be higher since they may have health problems that prohibit alcohol consumption.

Four indicators are included to reflect the health status of each respondent. Health conditions were captured with two dichotomous variables indicating whether a respondent has ever been diagnosed with a heart attack or a stroke. New health conditions are therefore included as soon as diagnosis occurs. Another dichotomous variable captures whether a respondent has missed "any work or study days due to illness" in the past month. This variable is particularly useful in understanding the extent to which respondents' livelihoods are affected by health. The final health

\footnotetext{
${ }^{2}$ An idiosyncrasy in this data is that although the majority of surveys were annual, two years were skipped. This analysis is based on data from 1994, 1995, 1996, 1998, 2000, 2001, 2002, 2003, 2004, 2005.

${ }^{3}$ Although other research based on RLMS data has used the top 20\% as a cutoff point for excessive alcohol consumption, sensitivity tests demonstrated that mortality was more highly associated with a narrower definition of excessive alcohol consumption.
} 
variable is self-rated health and indicates whether the respondent rates his/her health as being bad or very bad vs. average, good or very good.

Education was introduced categorically, in which respondents were classified as 1) not having completed secondary education, 2) having completed secondary education at least, including those who received vocational or technical training as well, and 3) having completed university education. The labor force variable harmonizes participation and occupational class information ${ }^{4}$ and consists of the following categories: 1) unemployed; 2) not participating in the labor force due to caring responsibilities; 3) not participating in the labor force because respondent is studying, retired, disabled or other; 4) a manual or routine worker; 5) a low-grade employee; 6) intermediate employee, or; 7) part of the "salariat" or professional class.

Other measures were introduced to capture level of resources as well. The most objective indicator of the level of financial resources would be earnings or income. Loss of personal earnings might best approximate the cause of psychosocial stress, given that stress is likely to increase if one is not able to contribute to or maintain one's contribution to household income. However, total household resources may smooth the loss of part or whole earnings. Therefore, household income might be the more appropriate measure for assessing resources and mobility. Moreover, the existence of wages implies that respondents remain in the labor market and that they are healthy. It may be that once unemployed or a health condition develops, an individual is less likely to be in the labor force. Therefore, a healthy worker effect may bias a measure that relies strictly on labor market involvement. For this reason, the sample is not limited to workers only and the impact of being downwardly mobile is considered after adjusting for all other labor market statuses, which should bias results downwards given that some level of health is required to maintain employment. ${ }^{5}$ As such, real household total income is assessed for its impact on the risk of death. This measure includes all home production and other household-level and individual-level income variables and reflects real household income since all amounts have been pegged to values in June 1992. This measure was also adjusted to reflect economies of scales, by using the revised OECD equivalence scale in which the first adult in the household retains the value of 1 , every additional adult is assigned the value of 0.5 and every child (less than 14 years old) is assigned a value of 0.3. The total household income is divided by this scale and the measure is, thus, the equivalent income per person within the household. Quartiles were constructed on a yearly basis and reflect the respondent's rank in a distribution of real adjusted income. Finally, some underreporting of household income is to be expected. Figure 1 demonstrates that income correlates as expected with household expenditure, which indicates that underreporting of income is likely more or less uniform and does not vary greatly according to income levels.

Figure 1. The gradient in income according to expenditure.

\footnotetext{
${ }^{4}$ Occupational class was constructed using ISER's approach that transforms 3-digit ISCO88 codes into the European Socioeconomic Classification, which is based on the EGP (Erikson-GoldthorpePortocarero) framework Rose \& Harrison (2007). ISCO88 codes were assigned with particular care to take into account Russian idiosyncrasies of occupations (Carolina Population Center 2009).

${ }^{5}$ Indeed, limiting my analyses to only those with a paid position in the labor market increased the magnitude of my findings for men.
} 


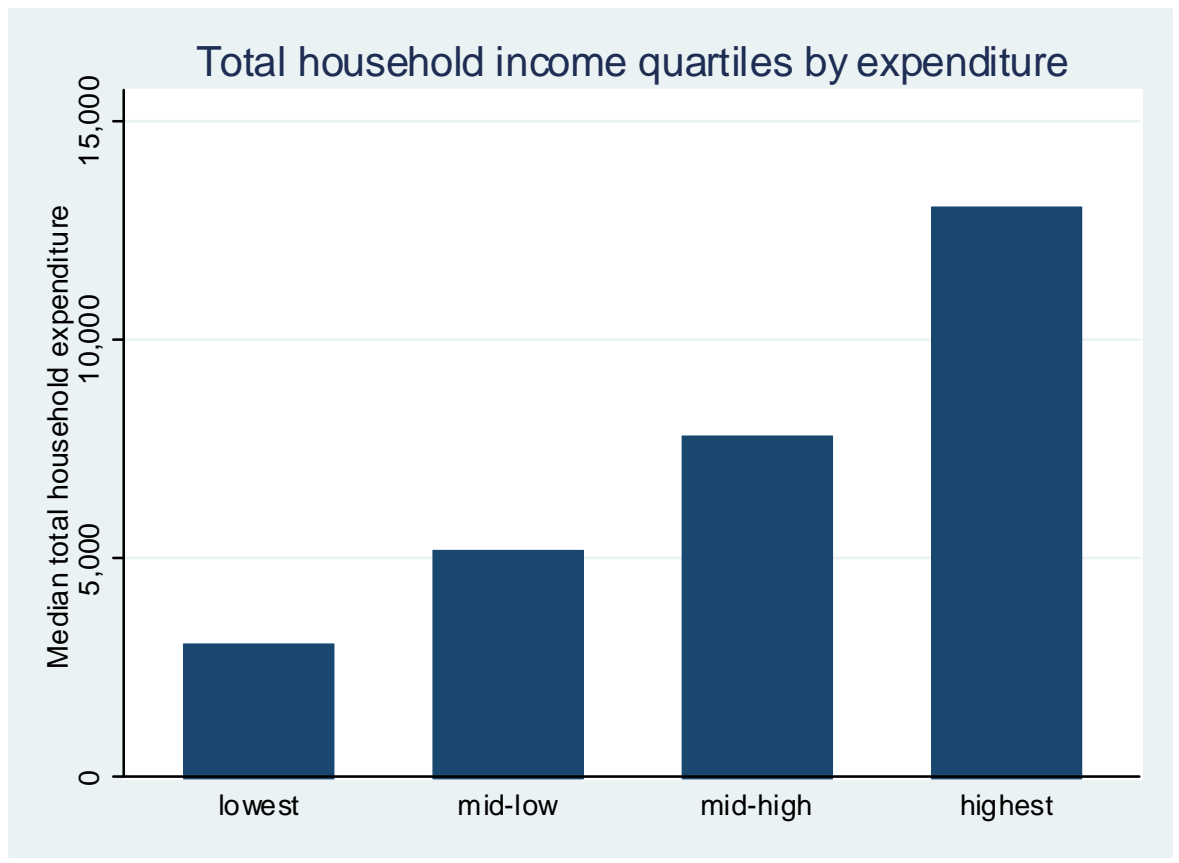

Source: author's calculations based on RLMS data

The second measure of resources does not rely on labor force participation either: it is subjective and indicates whether the respondent experienced a downward shift in the location on a 9-step latter that ranks personal wealth according to others. ${ }^{6}$ Because minute shifts in the steps of this ranking system may be arbitrary, the 9 steps are consolidated into 3 categories, representing the 3 bottom poorest steps, the 3 middle steps and the 3 highest steps. This measure may come closest to capturing the link between the economic context and health since it is possible that individuals or households experience a real loss in resources yet it may not always change their perception of how they fit into the larger context. Therefore, this measure introduces the important element of inequality, which may have intensified or lessened feelings over loss of resources. It may be that wage arrears and job loss diminished household income for many simultaneously, rendering the experience less personally significant. Indeed, RLMS data report between 40-63\% of all individuals experienced wage arrears or in-kind payment of wages from 1994-1998. Finally, although it comes at the price of objective clarity of external conditions, a subjective wealth measure moves one step deeper into the causal chain leading from the economic context to a health impact, in that it reflects the perceptions of individuals.

The dependent variable is death of the respondent and all deaths are reported by other members of the household in the survey following the year in which a death took place. Since deaths are reported through proxy respondents, it is not possible to capture deaths of individuals living alone. ${ }^{7}$ Moreover, all individuals who skipped participation in one or more survey rounds are censored at the moment they skip a round since it is not possible to accurately account for individuals' status during the missing waves. When studying relative changes in status from one year to the next, as in the case of mobility, those deaths in which we only have information for one wave

\footnotetext{
${ }^{6}$ The exact wording of the question in the survey is the following: "And now, please, imagine a 9-step ladder where on the bottom, the first step, stand the poorest people, and on the highest step, the ninth, stand the rich. On which step are you today?”

${ }^{7}$ Between 3 and $12 \%$ of all respondents in the sample lived alone, depending on the wave.
} 
are excluded as well, since it is not possible to capture mobility without at least two waves of data before the death. For these reasons, 267 deaths are excluded over the 11 years for which we have at least one wave of information about the individual. ${ }^{8}$ In the baseline static models that exclude the impact of mobility, 934 deaths are possible to study; whereas the dynamic models analyze 860 deaths. Rather than exclude observations and deaths to those who only completed one survey round before death, these extra deaths are kept in the static models in the interest of analyzing as large a sample of men and women as possible, despite incomparability with the reduced samples studied for mobility.

Attrition is a problem with the RLMS data since households and individuals sometimes left the sample by moving into a new dwelling. Each wave included new entrants to the survey to make up for the loss of movers. In general, these movers were not followed to remain in the survey. Denisova (2009) reports that $1-2 \%$ of all households or individuals who leave the sample are due to deaths, which is a negligible amount. However, she also reports that the average crude death rate given by the Russian statistical office is almost twice as high as the rate observed in the RLMS data, indicating that the RLMS presents a downward biased death rate, which could be due to attrition for other reasons that may be related later to death. This issue is important as it may be intimately related to the process being studied in this analysis. For example, an individual may experience downward social mobility or unemployment, be unable to make ends meet and have to move into a cheaper dwelling or co-reside with family/friends. If this is the case, it may be that the most detrimental experiences of downward mobility and unemployment are missing from the analysis. This form of bias, however, is downwards and means that actual statistical results presented in this study are weaker than they may be in reality.

On the other hand, Perlman and Bobak (2008, p. 94) find that, regardless of attrition, pooled age-specific death rates of men and women in the RLMS sample are quite similar to the average national Russian mortality rate. The greatest was found for women over the age of 60 . Nevertheless, logistic regression of those likely to attrit reveal that those who remain in the panel are a somewhat selected group. Using the characteristics of individuals in the final wave of data available for each respondent and predicting those who attrit relative to those who were censored either through death or participating in the final interview reveals the following differences (statistically significant at $\mathrm{p}<0.05$ ). First, those who attrit are more likely to be under the age of 40 than $45-59$, but less likely to be under the age of 40 than 60 . Attriters are also less likely to be non-drinkers and more likely to report being in poor health. They are more likely to be urban and not in a union, as well as have incomplete secondary education. Finally, they are less likely to be a low-grade employee than unemployed, not participating in the labor force or in any other occupational class. Many of these differences are to be expected considering that attrition in the case of this panel simply means that the respondent moved in the majority of cases. Nevertheless, these sample biases require caution in generalizing the results.

\footnotetext{
${ }^{8}$ The only statistically significant differences $(\mathrm{p}<0.05$; measured through logistic regression) between the characteristics of individuals who died after only one survey round or after having missed one or more survey rounds (taken from the last survey in which they participated) and the characteristics of those whose deaths were captured in the analysis, were that the excluded deaths were less likely to occur in the oldest age groups.
} 
The actual composition of the RLMS sample analyzed bears close resemblance to the total Russian sample in terms of education according to the All-Russian Population Census in 2002. Those who had completed tertiary education were $17.2 \%$ of the total Russian population in 2002 versus 18.3\% of the RLMS 2002 sample. A greater difference was found in regards to the lower two educational attainment groups: $56.6 \%$ of RLMS respondents completed secondary education and $25.1 \%$ did not, in contrast to $50 \%$ and $32.8 \%$ in the total population. This difference is to be expected given that we know those with very low education levels were the ones more likely to leave the sample through attrition. Besides this discrepancy, the education profile of the RLMS sample appears relatively similar to the general population.

Kaplan-Meier survival estimates in Figures 2 and 3 present descriptive information of the mortality estimates of the RLMS panel sample used in this analysis that died over the time under analysis, according to age groups and sex. As expected, women lived longer than men; near $80 \%$ of women over the age of 60 survived all years of analysis in contrast to less than $65 \%$ of men. And, as we know from much documentation on the scope and structure of increased mortality during transition from communism, men in the 40-60 year old age group were much more likely to die than women in the same age group. Particularly interesting is that the survival rates of men in the 50-54 age group were slightly better than men in the 45-49 year old age group. A perfect gradation by age is therefore not seen for the Russian men in this sample. Women's survival rates for all age groups under the age of 60 were more or less the same.

Figure 2. Survival estimates of RLMS sample, 1994-2005

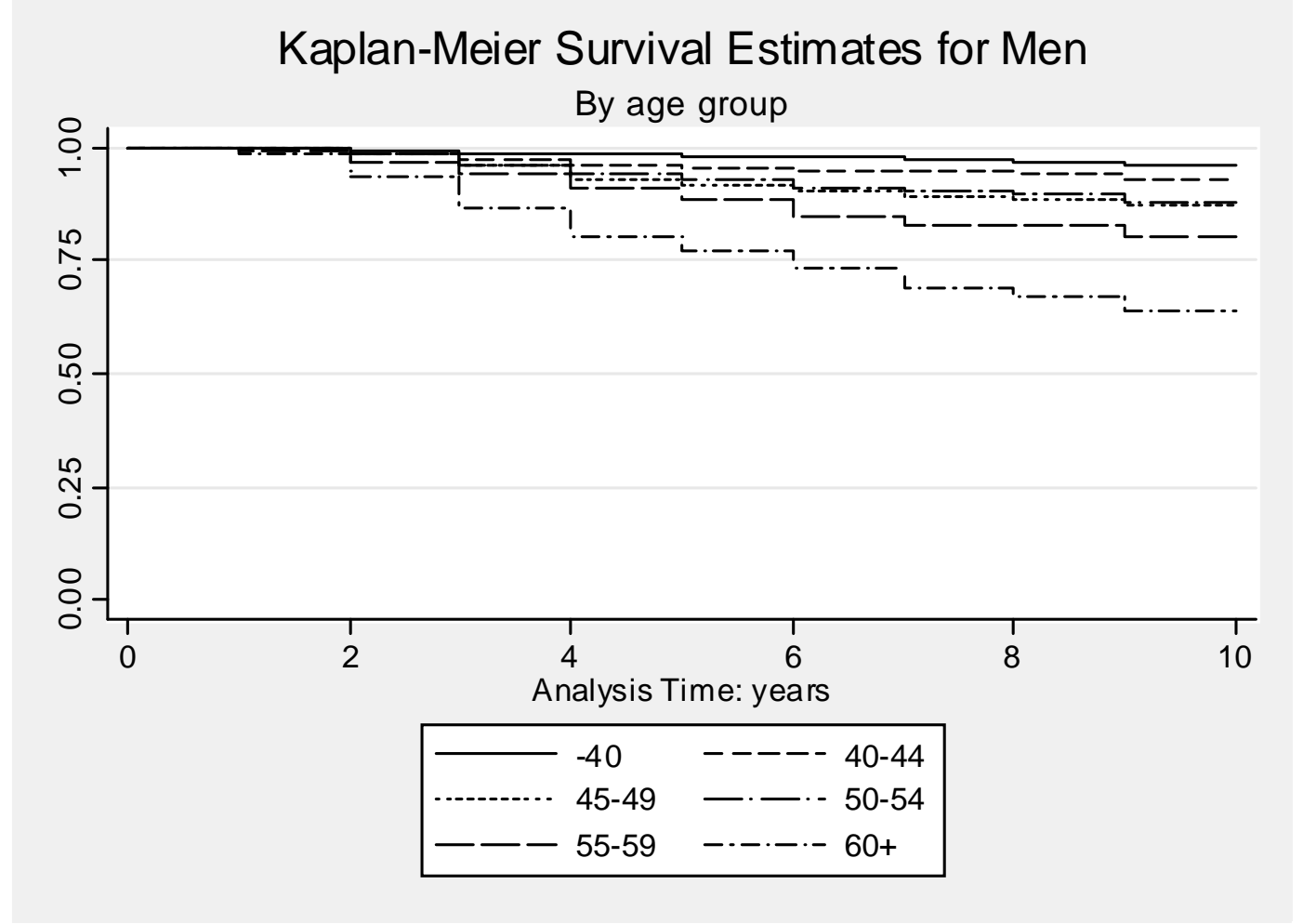

Figure 3. Survival estimates of RLMS sample, 1994-2005 


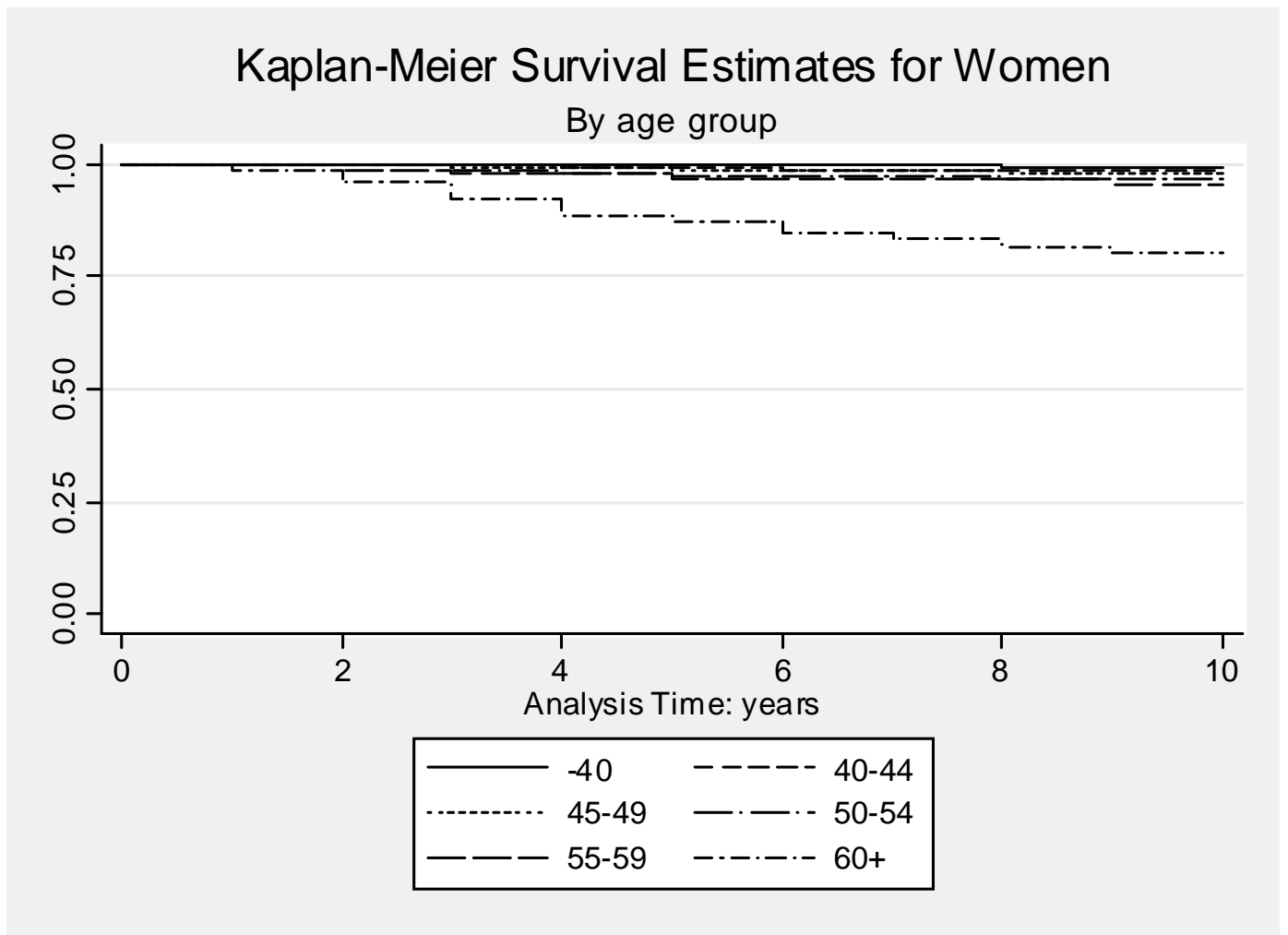

Source: Author’s calculations from RLMS data.

\section{Model and Analytical Strategy}

Cox proportional hazard models are used to estimate the impact of time-constant and time-varying factors on the risk of death, using a discrete event history format. The proportionality assumption required for using the Cox model was confirmed first by checking the consistent nearness of the predicted and observed values of a survival probability plot and, second, by observing a statistically insignificant interaction of time and age. These two tests ensure that a time-dependent process is not at work in these models. Robust standard errors are estimated by clustering on individuals.

The first step in this analysis is to analyze static characteristics, including unemployment, on the full sample, to understand the way these characteristics impact the risk of death on their own. The second step is to test the impact of experiencing downward mobility. The third step is to check the robustness of these results by assessing whether there is a health selection or alcohol consumption selection into downward social mobility or unemployment. It may be that it is not downward mobility or job loss that impacts death risks, but rather poor health or excessive alcohol consumption before downward mobility occurred that leads to both downward mobility and death. This aspect of the analysis, therefore, addresses the issue of endogeneity in the debate over the mortality crisis in Russia and addresses the assumption in the health divide literature that mobility occurs because of selection. The strategy used here is to control for health and alcohol consumption in the year preceding downward mobility. Still relying on at least two waves of data, the model now includes not only current characteristics and whether downward mobility or unemployment has occurred (at time t) but health status or excessive alcohol consumption status in the preceding year (t-1). The results of these models will indicate whether downward mobility or unemployment still has an impact on the risk 
of death when health and alcohol consumption are controlled for in the year preceding downward mobility. To further assess this issue, separate models analyzed the direct impact of health or excessive alcohol consumption on the risk of downward mobility and unemployment, adjusting for all other variables in the original models.

When working with mobility as an explanatory variable, there is risk of merely picking up effects that are related to the origin or destination class. Due to multicollinearity, since most people do not change classes from year to year, both origin or destination class cannot be included in the model simultaneously. Researchers assessing mobility within the health divide debate have two opposing perspectives that would recommend different approaches. Those who believe that longevity is related to initial conditions that factor into cumulative health would consider origin class the appropriate class to include. Conversely, if it is the impact of the destination class environment that matters, then destination class would be more important to control for. As destination class is controlled for in all the previous steps, the fourth step in this analysis is therefore to control for the confounding effect of origin class. The logic behind controlling for origin and destination class is somewhat different in this study, however. First, the "origin" class is not an indicator of early life conditions, but rather it is merely a measure of class in the preceding year; therefore, it may have less relevance. On the other hand, origin class will control for the fact that those who are in the lowest class already are not able to experience downward mobility. ${ }^{9}$ In regards to the traditional reasons for controlling for destination class, it is unlikely that respondents' health is detrimentally effected by destination class environment in the short time period that is considered here. Regardless, the issue of which class status should be controlled for is not easily resolved theoretically and, therefore, the models are run twice, once with origin class and once with destination class. A comparison of the results of the two might empirically tell us which status bears more weight on the risk of immediate death.

The final step is to test whether the impact of experiencing downward mobility or unemployment is lasting or short-term. This strategy includes comparing estimates of the impact of downward mobility and unemployment when the respondent is currently in that situation with the impact of having ever experienced unemployment or downward mobility. Because unemployment and downward mobility can only be captured in the waves in which the respondent participated, past negative labor market experiences that might have occurred in the earliest years of the transition are unfortunately not accounted for.

\section{RESULTS}

Tables 1-3 display the full model results of static characteristics on the risk of death for both men and women, analyzed separately. The results of these models are discussed together, since the impact of most variables does not greatly change depending on the measure of resources used. Over all three models, age has the expected and increasing impact on the risk of death, especially for women. The impact of age increases when labor force status is removed from the analysis as being in retirement shared the impact of age when it was included.

\footnotetext{
${ }^{9}$ This potential source of bias is not of great concern given that it would only weaken the results and not inflate them, since we know that health is poorest in the lowest occupational class ranking and since they are the ones that cannot experience downward mobility.
} 
Concerning risk factors, the impact of being a smoker was consistent across all three models with different resource measures, although there was some variation in the size of the relative risk. For men, being a smoker increased the risk of death from 32$33 \%$, whereas it increased the risk from $74-105 \%$ for women. In contrast to expectations, the relative risk of death for men in the top decile of alcohol consumption was not large, nor statistically significant, although in the expected direction. It varied from having a 3-11\% increase. However, excessive alcohol consumption greatly impacted women's relative risks of death; their risk of death was three times as high as women who did not consume such amounts of alcohol. Being a non-drinker also did not appear to matter greatly for men, while it almost doubled the risk of death for women, relative to drinkers.

One health condition also showed variation by sex. While the relative risk of death was between $40-43 \%$ higher for men if they had been diagnosed with a heart attack, a heart attack diagnosis had no statistically significant impact on women's risk. Both men and women were significantly impacted by diagnosis of stroke. Men had an increased risk of 64-71\%, whereas women had twice as high a risk as those who had not been diagnosed with a stroke. Concerning health status, subjective ratings of poor health were highly predictive of death in the next wave: death risks for both men and women were between two and three times higher and the risk was higher for men than women, relative to those whose health was average or good. Finally, neither for men nor women did the incidence of having missed work due to illness predict death with any statistical significance. The directional change in the impact of this indicator is consistent with whether labor force status is controlled for in the model, indicating the presence of a healthy worker effect.

In regards to the type of area in which the respondent lives, men were at a higher risk (22-28\%) of death if they lived in a rural area compared to an urban area. Type of area did not have a statistically significant relationship to mortality for women. Residing in a household in which the head is either retired or very young reduced the risk of death for women and men significantly.

Perhaps surprisingly, education was not related to the risk of death with statistical significance for men in these models. All the estimates for men are in the expected direction, however. For women, in contrast, having completed secondary or university education significantly reduced the risk of death (43-44\% and 33-48\%, respectively), relative to women who had not completed secondary school. The results for education are quite different in a reduced model, however, demonstrating that measures of the level of resources absorbs the impact of education for men, but not for women. Appendix B displays simplified models to show the straightforward impact of education, as well as smoking status, which reflect what we know from past research.

The impact of labor force status was as expected, in which non-participation due to caring for someone was statistically insignificant (although the direction of the estimates indicates it increases the risk of death for both men and women) and nonparticipation due to retirement, disability, studying or other unspecified reasons increases the risk of death. Most importantly, after adjusting for the impact of all these characteristics and statuses, men who were unemployed had twice as high a risk of 
death and women had a risk ten times as high, relative to men and women who were working as low-mid grade employees.

Turning now to the measures of resources, the first-in Table 1 -is occupational class, which did not prove to have a statistically significant relationship with mortality. Membership in none of the classes predicted a statistically significant higher death risk for men and the direction of the impact of membership was the same for all classes: belonging to the manual worker class, the intermediate employee class and the professional class all show a reduced risk of death, relative to those in the low-mid grade employee class. For women, membership in the lowest class (routine or manual workers) increased the risk of death to almost three times the risk of belonging to the low-mid grade class.

The model in Table 2 uses an alternative specification of resources that is one's location in a quartile distribution of real equivalent household income. In contrast to occupational class, a statistically significant relationship emerges between mortality and income for men. Relative to those in the lowest ranking of income, men in the mid-high and the highest ranks had a 30\% and 28\% lower risk of death, respectively. Men in the low-mid ranking of income had an increased risk of $6 \%$ but this result was not statistically significant. Along with all results for women being statistically insignificant, they were not in the expected direction.

Table 3 displays results of the final static model in which the measure of resources was location in a subjective wealth distribution. Here, a perfect gradient in health emerges for men, in which mid-ranking men had a 18\% lower risk and the highest ranking men had a 50\% lower risk of death, relative to the lowest ranking men. Women in the mid ranking had a $12 \%$ lower risk than women of the lowest ranking; women in the highest ranking were at a $3 \%$ higher risk, but none of the results for women were statistically significant. 
Table 1. Estimates of Static Characteristics and Occupational Class as a Measure of Resources

Cox Proportional Hazard Risks of Death in Russia, 1994-2005

\begin{tabular}{|c|c|c|}
\hline \multicolumn{3}{|c|}{$\begin{array}{c}\text { Relative Risks of Static Model 1: } \\
\text { Labor Force Participation and Class Status }\end{array}$} \\
\hline & Men & Women \\
\hline \multirow[t]{2}{*}{$<40$ years } & 1 & 1 \\
\hline & $2.01^{\star \star *}$ & $2.42^{\star}$ \\
\hline \multirow[t]{2}{*}{$40-44$} & $(0.44)$ & $(1.20)$ \\
\hline & $3.33^{\star \star \star}$ & $3.15^{\star \star \star}$ \\
\hline \multirow[t]{2}{*}{$45-49$} & $(0.63)$ & (1.33) \\
\hline & $2.64^{\star * *}$ & $1.03^{\star \star *}$ \\
\hline \multirow[t]{2}{*}{$50-54$} & $(0.58)$ & $(1.64)$ \\
\hline & $4.06^{\star \star \star}$ & $4.09 * \star \star$ \\
\hline \multirow[t]{2}{*}{$55-59$} & $(0.78)$ & $(1.61)$ \\
\hline & $5.56^{\star * \star}$ & $10.59 * \star \star$ \\
\hline \multirow[t]{2}{*}{$60+$} & $(1.24)$ & $(3.62)$ \\
\hline & $1.33^{\star \star \star}$ & $1.74^{\star \star}$ \\
\hline \multirow[t]{2}{*}{ smoker (ref: no) } & $(0.12)$ & $(0.45)$ \\
\hline & 1.03 & $3.46^{\star \star \star}$ \\
\hline \multirow[t]{2}{*}{ heavy alcohol cons (ref: no) } & $(0.18)$ & $(1.15)$ \\
\hline & 0.99 & $1.98^{\star \star \star}$ \\
\hline \multirow[t]{2}{*}{ non-drinker (ref: drinker) } & $(0.09)$ & $(0.31)$ \\
\hline & $1.40 * \star \star$ & 0.95 \\
\hline \multirow[t]{2}{*}{ heart attack diagnosed (ref: no) } & $(0.17)$ & $(0.20)$ \\
\hline & $1.64^{\star \star \star}$ & $2.03^{\star \star \star}$ \\
\hline \multirow[t]{2}{*}{ stroke diagnosed (ref: no) } & $(0.24)$ & $(0.34)$ \\
\hline & 1.24 & 1.38 \\
\hline \multirow[t]{2}{*}{ missed work from illness (ref: no) } & $(0.29)$ & $(0.64)$ \\
\hline & $2.81^{\star \star \star}$ & $2.72^{\star \star \star}$ \\
\hline perceives health as poor (ref: no) & $(0.28)$ & $(0.34)$ \\
\hline \multirow[t]{2}{*}{ urban residence } & 1 & 1 \\
\hline & 0.94 & 1.16 \\
\hline \multirow[t]{2}{*}{ townships } & $(0.17)$ & $(0.24)$ \\
\hline & $1.22^{\star *}$ & 0.95 \\
\hline rural residences & $(0.12)$ & $(0.11)$ \\
\hline \multirow[t]{2}{*}{ male-headed household } & 1 & 1 \\
\hline & 0.82 & 0.87 \\
\hline female-headed household & $(0.12)$ & $(0.14)$ \\
\hline & $0.63^{\star \star *}$ & $0.38^{* \star *}$ \\
\hline retired or young head & $(0.07)$ & $(0.04)$ \\
\hline & 1.04 & 1.08 \\
\hline not in union (ref: in union) & $(0.11)$ & $(0.12)$ \\
\hline incomplete secondary educ & 1 & 1 \\
\hline & 0.99 & $0.57^{\star * \star}$ \\
\hline complete secondary or more & $(0.10)$ & $(0.08)$ \\
\hline & 0.90 & $0.67^{\star \star}$ \\
\hline university or institute & $(0.13)$ & $(0.14)$ \\
\hline & $2.16^{\star \star \star}$ & $9.98^{\star \star \star}$ \\
\hline unemployed & $(0.44)$ & $(4.54)$ \\
\hline & 0.93 & 2.79 \\
\hline routine/manual worker & $(0.19)$ & $(1.81)$ \\
\hline low-mid grade employees & 1 & 1 \\
\hline & 0.60 & 0.24 \\
\hline intermediate employees/ers & $(0.25)$ & $(0.28)$ \\
\hline & 0.86 & 0.45 \\
\hline salariat & $(0.26)$ & $(0.52)$ \\
\hline & 3.51 & 2.58 \\
\hline caring for someone & $(3.27)$ & $(1.91)$ \\
\hline & $2.16^{\star * \star}$ & $5.94^{\star \star \star}$ \\
\hline other reasons not particip. & $(0.40)$ & $(3.56)$ \\
\hline \# of subjects & 8847 & 10622 \\
\hline \# of deaths & 544 & 384 \\
\hline Time at risk & 37195 & 50215 \\
\hline Log Pseudolikelihood & -4115.5 & -2861.3 \\
\hline Prob > chi2 & 0.0000 & 0.0000 \\
\hline Wald chi2 (25) & 780.54 & 628.38 \\
\hline
\end{tabular}


Note: Statistical significance: $*=10 \%, * *=5 \%, * * *=1 \%$

Table 2. Estimates of Static Characteristics and Real Equivalent Household Income as a Measure of Resources

Cox Proportional Hazard Risks of Death in Russia, 1994-2005

Relative Risks of Static Model 2:

\begin{tabular}{|c|c|c|}
\hline & Men & Women \\
\hline \multirow[t]{2}{*}{$<40$ years } & 1 & 1 \\
\hline & $1.83^{\star \star \star}$ & $2.29 *$ \\
\hline \multirow[t]{2}{*}{$40-44$} & $(0.42)$ & $(1.15)$ \\
\hline & $2.27^{\star \star \star}$ & $3.36 * \star \star$ \\
\hline \multirow[t]{2}{*}{$45-49$} & $(0.63)$ & $(1.45)$ \\
\hline & $2.89 * * *$ & $5.40 * \star *$ \\
\hline \multirow[t]{2}{*}{$50-54$} & $(0.64)$ & $(2.21)$ \\
\hline & $4.64^{\star \star \star}$ & $7.79 * \star \star$ \\
\hline \multirow[t]{2}{*}{$55-59$} & $(0.89)$ & $(3.04)$ \\
\hline & $9.75^{\star \star \star}$ & $23.23^{\star \star \star}$ \\
\hline \multirow[t]{2}{*}{$60+$} & $(1.71)$ & $(7.67)$ \\
\hline & $1.32^{\star \star \star}$ & $2.05^{\star \star \star}$ \\
\hline \multirow[t]{2}{*}{ smoker (ref: no) } & $(0.12)$ & $(0.50)$ \\
\hline & 1.11 & $3.60 * * *$ \\
\hline \multirow[t]{2}{*}{ heavy alcohol cons (ref: no) } & $(0.20)$ & $(1.24)$ \\
\hline & 1.03 & $2.17^{\star \star \star}$ \\
\hline \multirow[t]{2}{*}{ non-drinker (ref: drinker) } & $(0.09)$ & $(0.38)$ \\
\hline & $1.43^{\star \star \star}$ & 0.93 \\
\hline \multirow[t]{2}{*}{ heart attack diagnosed (ref: no) } & $(0.18)$ & $(0.20)$ \\
\hline & $1.69 * \star \star$ & $2.08^{\star \star \star}$ \\
\hline \multirow[t]{2}{*}{ stroke diagnosed (ref: no) } & $(0.25)$ & $(0.36)$ \\
\hline & 1.01 & 0.88 \\
\hline \multirow[t]{2}{*}{ missed work from illness (ref: no) } & $(0.23)$ & $(0.41)$ \\
\hline & $3.09 * \star \star$ & $2.92^{\star \star \star}$ \\
\hline perceives health as poor (ref: no) & $(0.31)$ & $(0.38)$ \\
\hline \multirow[t]{2}{*}{ urban residence } & 1 & 1 \\
\hline & 0.96 & 1.15 \\
\hline \multirow[t]{2}{*}{ township } & $(0.18)$ & $(0.25)$ \\
\hline & $1.26^{\star *}$ & 0.99 \\
\hline rural residence & $(0.12)$ & $(0.11)$ \\
\hline \multirow{2}{*}{ male-headed household } & 1 & 1 \\
\hline & 0.80 & 0.87 \\
\hline \multirow[t]{2}{*}{ female-headed household } & $(0.15)$ & $(0.14)$ \\
\hline & $0.61^{\star \star \star}$ & $0.37 * \star \star$ \\
\hline \multirow[t]{2}{*}{ retired or young head } & $(0.07)$ & $(0.05)$ \\
\hline & 1.07 & 1.09 \\
\hline not in union (ref: in union) & $(0.11)$ & $(0.13)$ \\
\hline \multirow[t]{2}{*}{ incomplete secondary educ } & 1 & 1 \\
\hline & 1.01 & $0.56^{\star * *}$ \\
\hline \multirow[t]{2}{*}{ complete secondary or more } & $(0.10)$ & $(0.08)$ \\
\hline & 0.90 & $0.52^{\star * \star}$ \\
\hline university or institute & $(0.13)$ & $(0.11)$ \\
\hline \multirow[t]{2}{*}{ Lowest $\mathrm{HH}$ income (<25\%) } & 1 & 1 \\
\hline & 1.06 & 1.19 \\
\hline Low-mid $\mathrm{HH}$ income (25-50\%) & $(0.12)$ & $(0.16)$ \\
\hline & $0.70^{\star \star}$ & 1.21 \\
\hline Mid-high $\mathrm{HH}$ income (50-75\%) & $(0.09)$ & $(0.18)$ \\
\hline & $0.72^{\star \star}$ & 1.05 \\
\hline Highest $\mathrm{HH}$ income (>75\%) & $(0.10)$ & $(0.18)$ \\
\hline \# of subjects & 8740 & 10465 \\
\hline \# of deaths & 531 & 373 \\
\hline Time at risk & 36010 & 47796 \\
\hline Log Pseudolikelihood & -4011.3 & -2780.8 \\
\hline Prob > chi2 & 0.0000 & 0.0000 \\
\hline Wald chi2 (22) & 829.17 & 696 \\
\hline
\end{tabular}

Note: Statistical significance: $*=10 \%, * *=5 \%, * * *=1 \%$ 
Table 3. Estimates of Static Characteristics and Subjective Wealth Distribution as a Measure of Resources

Cox Proportional Hazard Risks of Death in Russia, 1994-2005

\begin{tabular}{|c|c|c|}
\hline \multicolumn{3}{|c|}{$\begin{array}{c}\text { Relative Risks of Static Model 3: } \\
\text { Location in the Subjective Wealth Distribution }\end{array}$} \\
\hline & Men & Women \\
\hline \multirow[t]{2}{*}{$<40$ years } & 1 & 1 \\
\hline & $1.86^{\star \star \star}$ & 1.93 \\
\hline \multirow[t]{2}{*}{$40-44$} & $(0.41)$ & $(0.95)$ \\
\hline & $3.21^{\star \star \star}$ & $2.83^{\star *}$ \\
\hline \multirow[t]{2}{*}{$45-49$} & $(0.61)$ & $(1.18)$ \\
\hline & $2.69 * * *$ & $4.55^{\star \star \star}$ \\
\hline \multirow[t]{2}{*}{$50-54$} & $(0.59)$ & $(1.79)$ \\
\hline & $4.31^{\star \star \star}$ & $6.68^{\star \star *}$ \\
\hline \multirow[t]{2}{*}{$55-59$} & $(0.82)$ & $(2.49)$ \\
\hline & $9.01^{\star \star \star}$ & $19.97^{\star \star \star}$ \\
\hline \multirow[t]{2}{*}{$60+$} & $(1.57)$ & $(6.16)$ \\
\hline & $1.33^{\star \star \star}$ & $1.93^{\star \star \star}$ \\
\hline \multirow[t]{2}{*}{ smoker (ref: no) } & $(0.12)$ & $(0.48)$ \\
\hline & 1.06 & $3.62^{* \star *}$ \\
\hline \multirow[t]{2}{*}{ heavy alcohol cons (ref: no) } & $(0.19)$ & $(1.20)$ \\
\hline & 1.03 & $2.04^{* * *}$ \\
\hline \multirow[t]{2}{*}{ non-drinker (ref: drinker) } & $(0.09)$ & $(0.35)$ \\
\hline & $1.43^{\star \star \star}$ & 1.01 \\
\hline \multirow[t]{2}{*}{ heart attack diagnosed (ref: no) } & $(0.18)$ & $(0.21)$ \\
\hline & $1.71^{\star \star \star}$ & $1.97^{* * *}$ \\
\hline \multirow[t]{2}{*}{ stroke diagnosed (ref: no) } & $(0.25)$ & $(0.34)$ \\
\hline & 0.93 & 0.86 \\
\hline \multirow[t]{2}{*}{ missed work from illness (ref: no) } & $(0.21)$ & $(0.40)$ \\
\hline & $3.10 * \star \star$ & $2.81^{\star \star \star}$ \\
\hline perceives health as poor (ref: no) & $(0.31)$ & $(0.36)$ \\
\hline \multirow[t]{2}{*}{ urban residence } & 1 & 1 \\
\hline & 1.01 & 1.09 \\
\hline \multirow[t]{2}{*}{ township } & $(0.18)$ & $(0.23)$ \\
\hline & $1.28^{* \star *}$ & 0.97 \\
\hline rural residence & $(0.12)$ & $(0.11)$ \\
\hline \multirow{2}{*}{ male-headed household } & 1 & 1 \\
\hline & 0.80 & 0.90 \\
\hline \multirow[t]{2}{*}{ female-headed household } & $(0.15)$ & $(0.14)$ \\
\hline & $0.64^{* * *}$ & $0.38^{* * *}$ \\
\hline \multirow[t]{2}{*}{ retired or young head } & $(0.07)$ & $(0.04)$ \\
\hline & 1.15 & 1.04 \\
\hline not in union (ref: in union) & $(0.11)$ & $(0.12)$ \\
\hline \multirow{2}{*}{ incomplete secondary educ } & 1 & 1 \\
\hline & 0.99 & $0.57^{* * *}$ \\
\hline complete secondary or more & $(0.10)$ & $(0.08)$ \\
\hline & 0.84 & $0.54^{\star \star \star}$ \\
\hline university or institute & $(0.12)$ & $(0.11)$ \\
\hline lowest ranking of subjective wealth & 1 & 1 \\
\hline & $0.82^{\star *}$ & 0.88 \\
\hline mid ranking of subjective wealth & $(0.07)$ & $(0.11)$ \\
\hline & $0.50^{*}$ & 1.03 \\
\hline high ranking of subjective wealth & $(0.20)$ & $(0.47)$ \\
\hline & $1.68^{\star *}$ & $2.21^{\star \star \star}$ \\
\hline missing & $(0.38)$ & $(0.38)$ \\
\hline \# of subjects & 8847 & 10622 \\
\hline \# of deaths & 544 & 384 \\
\hline Time at risk & 37195 & 50215 \\
\hline Log Pseudolikelihood & -4134 & -2875.8 \\
\hline Prob > chi2 & 0.0000 & 0.0000 \\
\hline Wald chi2 (18) & 824.84 & 750.59 \\
\hline
\end{tabular}

Note: Statistical significance: $*=10 \%, * *=5 \%, * * *=1 \%$ 
The next results discussed (Table 4) are those that assess whether the relationship between unemployment and mortality was attenuated when controlling for past alcohol or poor health, which may have led to job loss. Unemployment still increases the risk of death for men by $82 \%$ when controlling for alcohol consumption and $89 \%$ for women, both of which are statistically significant results. The risk of death when having been an excessive alcohol drinker in the previous wave is not statistically significant, although it is in the expected direction (increase of $25 \%$ in the risk of death). Controlling for poor health also does not greatly alter the relationship between unemployment and risk of death for men and women; however, the impact of having been in poor health in the previous wave increases the risk of death by $45 \%$ and this result is highly statistically significant. Finally, having ever been unemployed in the years surveyed here, as a long-term effect, still increases the risk of death for men by (66\%) than only having been unemployed in a current spell, whereas the results for women decrease to only an increase of $31 \%$, which is not statistically significant.

Table 4. Estimates of Unemployment Models

Cox Proportional Hazard Risks of Death in Russia, 1994-2005

\begin{tabular}{|c|c|c|c|}
\hline \multicolumn{4}{|c|}{ Relative risks of experiencing unemployment } \\
\hline & Past alcohol & Past health & Ever experienced \\
\hline \multirow[t]{2}{*}{ Men: not unemployed } & 1 & 1 & 1 \\
\hline & $1.82^{\star \star \star}$ & $1.83^{\star \star \star}$ & $1.66^{\star \star \star}$ \\
\hline Men: unemployed & $(0.29)$ & $(0.29)$ & $(0.20)$ \\
\hline \multirow[t]{2}{*}{ Women: not unemployed } & 1 & 1 & 1 \\
\hline & $1.89^{\star \star}$ & $1.95^{\star \star}$ & 1.31 \\
\hline Women: unemployed & $(0.59)$ & $(0.61)$ & $(0.24)$ \\
\hline Past excessive alcohol consumption & $\begin{array}{l}1.25 \\
(0.20)\end{array}$ & & \\
\hline Past health status was poor & & $\begin{array}{l}1.45^{\star \star \star} \\
(0.12)\end{array}$ & \\
\hline \# of subjects & 14804 & 14804 & 14804 \\
\hline \# of deaths & 860 & 860 & 860 \\
\hline Time at risk & 68111 & 68111 & 68111 \\
\hline Log Pseudolikelihood & -7062.98 & -7054.30 & -7063.21 \\
\hline Prob > chi2 & 0.0000 & 0.0000 & 0.0000 \\
\hline Wald chi2 & 1726.92 & 1743.69 & 1665.07 \\
\hline
\end{tabular}

Note: Statistical significance: $*=10 \%, * *=5 \%, * * *=1 \%$. Results are adjusted for current age, health conditions, health status, alcohol and smoking status, urban/rural residence, household type, union status, and education.

The results of the dynamic models, analyzing the impact of change in one's level of resources differ between men and women. Table 5 displays the results of downward mobility according to a downward shift in the subjective wealth distribution. ${ }^{10}$ Downward mobility did not prove to have a statistically significant relationship with women's risk of death. However, it increased the risk of death for men by 33\% and this relationship was highly statistically significant. Moreover, none of the extra models that were implemented to check the robustness of these results altered the relationship between mobility and mortality for men. Whether controlling for the possibility that the impact of mobility is related to alcohol consumption or health status in the previous wave, men who experienced downward mobility had a 33-34\% higher risk of death than men who did not experience downward mobility. As in the case of the unemployment models, past excessive alcohol consumption did not prove

\footnotetext{
${ }^{10}$ For reasons of space, the results for downward mobility according to a decrease in ranking of real equivalent household income are not displayed since this measure or form of mobility did not prove to have a statistically significant relationship with the risk of death. However, it is worth noting that the results were in the expected direction, i.e., experiencing this form of downward mobility increased the risk of death.
} 
to be related to death with statistical significance, whereas being in poor health in the previous wave was statistically significant and increased the risk of death by $39 \%{ }^{11}$ Adjusting the models to include the subjective wealth distribution rank that individuals reported before downward mobility occurred further strengthened the relationship between downward mobility and mortality by increasing the impact to $52 \%$. Moreover, having ranked oneself in the mid-category of wealth distribution decreased the risk of death by $17 \%$, relative to being in the lowest rank. The results of this specific model, which controls for origin state, are in line with expectations; we should expect weaker results in the models that do not control for the origin state since we would expect health to be poorest in the lowest ranking and those in the lowest ranking cannot experience downward mobility. Not shown in the table, for reasons of space, are interactions between downward mobility and previous wealth ranking. It appears that the negative health effect of downward mobility for men is driven by those in the middle ranking who experience a fall, not those in the highest (according to statistical significance, although results for both the interaction for the mid and highest rank show an increase in mortality risk when downwardly mobile). Finally, re-specifying the downward mobility measure to one that indicates whether the respondent has ever experienced downward mobility (i.e., in the waves covered here), did not prove to better estimate the impact of downward mobility.

Table 5. Estimates of Downward Mobility Models

\begin{tabular}{|c|c|c|c|c|c|}
\hline \multicolumn{6}{|c|}{ Relative risks of a downward shift in subjective ranking of wealth } \\
\hline & Mobility & Past alcohol & Past health & Origin state & $\overline{\text { Ever experienced }}$ \\
\hline Men: no downward mobilty & 1 & 1 & 1 & 1 & 1 \\
\hline & $1.33^{* \star *}$ & $1.33^{* \star *}$ & $1.34^{\star \star \star}$ & $1.52^{\star \star *}$ & 1.05 \\
\hline Men: downward mobilty & $(0.14)$ & $(0.14)$ & $(0.14)$ & $(0.19)$ & $(0.10)$ \\
\hline Women: no downward mobilty & 1 & 1 & 1 & 1 & 1 \\
\hline & 0.96 & 0.96 & 0.97 & 1.15 & $0.83^{\star}$ \\
\hline Women: downward mobilty & $(0.14)$ & $(0.14)$ & $(0.15)$ & $(0.20)$ & $(0.09)$ \\
\hline Past excessive alcohol consumption & & $\begin{array}{l}1.27 \\
(0.19)\end{array}$ & & & \\
\hline Past health status was poor & & & $\begin{array}{l}1.39 * * * \\
(0.11)\end{array}$ & & \\
\hline Past lowest ranking of subj. wealth & & & & 1 & \\
\hline Past mid ranking of subj. wealth & & & & $\begin{array}{l}0.83^{\star *} \\
(0.08) \\
0.88\end{array}$ & \\
\hline Past highest ranking of subj. wealth & & & & $(0.24)$ & \\
\hline \# of subjects & 14804 & 14804 & 14804 & 14380 & 14804 \\
\hline \# of deaths & 860 & 860 & 860 & 792 & 860 \\
\hline Time at risk & 68111 & 68111 & 68111 & 64078 & 68111 \\
\hline Log Pseudolikelihood & -7027.81 & -7026.85 & -7020.00 & -6447.30 & -6936.23 \\
\hline Prob > chi2 & 0.0000 & 0.0000 & 0.0000 & 0.0000 & 0.0000 \\
\hline Wald chi2 & 1591.53 & 1595.83 & 1610.33 & 1610.56 & 1610.33 \\
\hline
\end{tabular}

Note: Statistical significance: $*=10 \%, * *=5 \%, * * *=1 \%$. Results are adjusted for current age, health conditions, health status, alcohol and smoking status, urban/rural residence, household type, union status, and education.

\section{DISCUSSION AND CONCLUSIONS}

These results indicate many findings worth considering. Unemployment appears to be strongly related to the risk of death for men, no matter how the relationship is

\footnotetext{
${ }^{11}$ Further investigation of selection into downward mobility or unemployment — using separate models to analyze the direct impact of health or excessive alcohol consumption on the risk of downward mobility or unemployment for those participating in the labor market, adjusting for all other variables in the original models-revealed no statistically significant relationship. Results are not shown for reasons of space, but they are available upon request.
} 
measured-immediate or prolonged, continued or short-term-and no matter which mediating variables, such as past alcohol consumption and poor health, are included. When measured as a relative risk against those who were employed in a low-mid grade job, the impact of unemployment was strikingly high for women. When measured as a relative risk simply against all those who were participating in the labor force and those who were not, the relationship remained strong and was similar for men and women. This relationship is an important finding in a context in which unemployment steadily increased during the 1990s and that is once again facing an economic crisis. In addition, the finding that unemployment matters and matters even after a respondent returns to paid employment for men confirms the long-lasting relationship Strully (2009) found in her results for the U.S.

The results of other variables in the static models yield very different results for men and women. The relationship between mortality and education for women was not attenuated by including measures of resources. In contrast, the relationship between education and mortality for men was no longer statistically significant when the level of resources was included in the model. Moreover, while membership in the lowest occupational class appears to be somewhat related to deaths for women, higher objective and subjective rankings of wealth or income appear to lessen the risk of death for men. The strongest of these results involved real equivalent household income. Additionally, reducing the sample to only wage-earners reveals the expected and statistically significant mortality gradient by wage: ${ }^{12}$ men in the $50-75 \%$ quartile of the wage distribution had a $49 \%$ lower risk of death, relative to men in the bottom quartile, and men in the top quartile had a 55\% lower risk. Men in the $25-50 \%$ quartile were $34 \%$ less likely to die, but this estimate was not statistically significant. None of the estimates for location in the wage distribution were significant for women. The difference in these results according to sex may be due to idiosyncrasies of the measures, especially in light of the fact that all results are already controlling for education level, which in and of itself should absorb much of the impact of long-term risk exposure.

Estimates of the impact of downward mobility on mortality revealed a robust and statistically significant relationship for men, but not for women. However, this relationship is statistically significant only when the measure is a direct reflection of how the respondent feels about his/her current class compared to class in the previous wave (i.e., subjectively measured and not objectively). Theoretically, this may be the most fitting indicator of downward mobility. Although real total household income most directly reflects financial circumstances, the experience of downward mobility may be just as meaningful, or more so, when experienced subjectively and in relation to individual perceptions of status and inequality (Runciman 1971; Watson 1995). Moreover, the objective measure refers to the household and not just to the individual. This difference may be important, since ranking is mediated by others in the household, and could work in opposite ways. It may be that the total household welfare matters more than individual income; conversely, it may be just as likely that one's own contribution to household welfare is what matters most. The essence of the subjective ranking is the latter, since it is a measure of personal wealth.

\footnotetext{
${ }^{12}$ Not shown for reasons of space but full results are available upon request.
} 
That a more direct form of measuring resources, objectively or subjectively, and that downward mobility appear to matter more for men's health than women's remains an area of speculation. The differential impact may be due to women experiencing stress differently in terms of their mental, emotional, behavioral and physical responses to stress. Or, men may perceive their role in providing material resources to be of greater importance to household welfare, leaving them with feelings of greater pressure and responsibility. Without doubt, much research along these lines would help shed light on causal mechanisms at work, which are not covered in the scope of this study. For example, empirical investigation of Watson's (1995) theoretical framework may yield evidence to support her idea that the devaluation of the public sphere and increasing importance of the private sphere left men without a realm in which their needs were adequately fulfilled and their role valorized. In any case, this study does provide evidence that it is not strictly a matter of selection into unemployment and downward mobility on the basis of poor health and excessive alcohol consumption that relates these experiences to mortality. Furthermore, findings that are more relevant to men are welcomed in this study given that men's mortality increases drove the mortality crisis in Russia.

Much room exists still for exploration into the relationship between downward mobility and mortality. One important limitation of this study is that the link between downward mobility and mental or emotional well-being, as well as the link between well-being and physical conditions that lead to death remain unidentified and are not commented upon in this study. Further research into causal mechanisms is needed. Some important biases in this research must also be acknowledged. First, because the study begins in 1994, there is left truncation in the sample since many of the most susceptible people, including those most unfortunate in the labor market, may have died in the first peak of the economic and mortality crises in Russia. Because of the great number of lives lost in the early years of transition, living until 1994 in a sense may have already introduced selection bias into the sample. Furthermore, attrition has likely biased the sample composition, even though the surveyed sample appears relatively similar to the total population. Another potential source of bias lies in how the dependent variable is measured; because a second person in the household is necessary for a report of death, the sample excludes all those who live alone. Therefore, the results cannot be generalized beyond the mortality of people who coreside with another person. This is perhaps the most important reason the results of this study cannot be widely generalized. We know that it is men without partners who were particularly at risk during the transition (Watson 1995) and these men are more likely to live alone.

To summarize, this study illuminated a new link between downward mobility and mortality: one that is immediate, does not rely on long-term risk exposure, is not strictly related to selection into mobility and is indicative of what we would expect if stress were at work. Therefore, I have proposed a new and worthwhile time-frame in which to analyze downward mobility that is appropriate to this context. The same results hold for the relationship between unemployment. This study has gone beyond traditional approaches and variables to suggest a strategy for assessing the contribution of economic transition and crisis to mortality during the turbulent transition from communism. Four main findings emerge. First, unemployment substantially increases the risk of mortality for both men and women, relative to workers of a low-mid occupational class or relative to those working in general or not 
participating in the labor force. Second, downward mobility impacts men's mortality risks, if it is measured in a way that avoids the healthy worker effect and is measured subjectively. Third, the impact of downward mobility is limited, at least with statistical significance, to currently being in a state of downward mobility only; whereas the impact of unemployment continues after the spell of unemployment has ended.

Fourth, excessive alcohol consumption and poor health did not appear to predict downward mobility or unemployment directly, nor did they attenuate the impact of downward mobility on death, measured currently and in the past wave. However, this result must be taken with caution; there are at least three reasons why the impact of excessive alcohol consumption may not be entirely accounted for in this study. First, individuals with the most severe alcohol consumption tendencies are likely selected out of being in the sample due to the disruption in private lives this health behavior entails. Second, the questions used to assess excessive alcohol consumption in this survey may not be the most appropriate. Both questions about non-beverage alcohol consumption (e.g., surrogate alcohols in the form of colognes, medicines, etc.) and "markers of problem drinking" have been shown to be important in assessing the nature and impact of alcohol consumption in Russia (Leon et al. 2007). Questions related to amount too easily lead to underreporting of consumption, which Nemtsov (2003) claims is a problem in the RLMS data, especially for women. Third, the relationship between alcohol consumption and mortality may be obscured in this survey due to the short-dose response time of harmful alcohol consumption. Because the surveys are generally administered annually, the information in the last wave before death may not reflect the most important information. In other words, we may be missing an important increase in alcohol consumption that quickly leads to death (Perlman \& Bobak 2008).

In the end, the results of this study demonstrate how economic turbulence matters to health. Given widespread economic recession and increasing labor market disruption, downward mobility and unemployment is not unique to economies undergoing market reform. Depending on institutional differences, such as the degree of labor market regulation and safety nets in place, the occurrence and impact of downward mobility and unemployment will likely vary. Some studies have already shown this to be true (e.g., Jäntti et al. 2000 and Martikainen et al. 2007 on the Finish case versus Strully 2009 on the U.S. case). Nevertheless, in the current economic climate, the traditional relationship argued to exist between health and downward mobility must be reconceptualized. Turbulent labor markets may create more downwardly mobile individuals than ever before. Drawing conclusions about the health of these individuals merely based on the assumption that they selected themselves into downward mobility and unemployment through poor health or health behaviors would be erroneous. Therefore, these findings support the need for further theoretical and empirical development of the relationship between health and turbulent economic contexts. 
Acknowledgements

I am grateful to Gosta Esping-Andersen, Jan Hoem, Alexandra Pittman and Vladimir Shkolnikov for their helpful suggestions in the design and implementation of this study. All errors are my own.

\section{References}

Abdala, F., Geldstein, R., \& Mychaszula, S. (2000). Economic restructuring and mortality changes in Argentina: Is there any connection? In G.A. Cornia \& R. Paniccia (Eds.), The mortality crisis in transitional economies (pp. 328-350). New York: Oxford University Press.

All-Russian Population Census. (2002). Vol. 3 (Book 1) Education and Training.

Barr, N. (2001). Reforming welfare states in post-communist countries. In L.T. Orlowski (Ed.), Transition and Growth in Post-Communist Countries: The TenYear Experience (pp. 169-218). Cheltenham, UK: Edward Elgar, 169-218.

Blanchard, O. (1997). The Economics of Post-Communist Transition. Clarendon Lectures in Economics. New York: Oxford University Press. Blazek, J. \& Dzúrová, D. (2000). The decline of mortality in the Czech Republic during the transition: A counterfactual case study. In G.A. Cornia \& R. Paniccia (Eds.), The mortality crisis in transitional economies (pp. 303-327). New York: Oxford University Press.

Blazek, J. \& Dzúrová, D. (2000). The decline of mortality in the Czech Republic during the transition: A counterfactual case study. In G.A. Cornia \& R. Paniccia (Eds.), The mortality crisis in transitional economies (pp. 303-327). New York: Oxford University Press.

Brainerd, E., \& Cutler, D.M. (2005). Autopsy of an Empire: Understanding Mortality in Russia and the Former Soviet Union. Journal of Economic Perspectives 19(1), 107-30.

Carolina Population Center. (2009). Occupational Coding. Retrieved from the University of North Carolina Chapel Hill's Carolina Population Center Website on March 19, 2009: http://www.cpc.unc.edu/projects/rlms/data/ occupationalcoding.html

Claussen, B., Smits, J., Naess, O., \& Davey Smith, G. (2005). Intergenerational mobility and mortality in Oslo: Social selection versus social causation. Social Science \& Medicine, 61, 2513-2520.

Cockerham, W. (1999). Health and social change in Russia and Eastern Europe. New York \& London: Routledge.

Cockerham, W. (2000). Health lifestyles in Russia. Social Science \& Medicine, 51, 1313-1324.

Cockerham, W. (2006). Class Matters: Health lifestyles in post-Soviet Russia. Harvard International Review, Spring, 64-68. 
Cornia, G.A. (2000). Short-term, long-term, and hysteresis mortality models: A review. In G.A. Cornia \& R. Paniccia (Eds.), The mortality crisis in transitional economies (pp. 59-80). New York: Oxford University Press.

Cornia, G.A., Paniccia, R. (1998). The transition's Population crisis: Nuptiality, Fertility, and Mortality Changes in Severely Distressed Economies. In M. LiviBacci \& G. de Santis (Eds.), Population and Poverty in the Developing World (pp. 217-249). Oxford: Clarendon press.

Dahl, E., \& Kjaersgaard, P. (1993). Social mobility and inequality in mortality: An assessment of the health selection hypothesis. European Journal of Public Health, 3, 124-132.

Davey Smith, G., Hart, C., Blane, D., Gillis, C., \& Hawthorne, V. (1997). Lifetime socioeconomic position and mortality: Prospective observational study. BMJ, 314, 547.

Denisova, I. (2009). Mortality in Russia: Microanalysis. Centre for Economic and Financial Research at New Economic School Working Paper, No. 128.

Erikson, R., \& Goldthorpe, J. (1992). Changing classes. Stratification and mobility in post-industrial societies. Oxford: Oxford University Press.

Hart, C., Davey Smith, G., Blane, D. (1998). Social mobility and 21 year mortality in a cohort of Scottish men. Social Science and Medicine, 47(8), 1121-1130.

Hemmingsson, T., \& Lundberg, I. (2005). Can large relative mortality differences between socio-economic groups aong Swedish men be explained by risk indicator-associated social mobility? European Journal of Public Health, 1-5.

Jäntti, M., Martikainen, P., \& Valkonen, T. (2000). When the welfare state works: Unemployment and mortality in Finland. In G.A. Cornia \& R. Paniccia (Eds.), The mortality crisis in transitional economies (pp. 351-369). New York: Oxford University Press.

Krumins, J., \& Usackis, U. (2000). The mortality consequences of the transition to market economy in Latvia, 1991-1995. In G.A. Cornia \& R. Paniccia (Eds.), The mortality crisis in transitional economies (pp. 227-252). New York: Oxford University Press.

Leon, D., \& Shkolnikov, V. (1998). Social stress and the Russian mortality crisis. Journal of the American Medical Association, 279, 790-791.

Leon, D., Saburova, L., Tomkins, S., et al. (2007). Hazardous drinking and premature mortality in Russia: A population based case-control study. Lancet, 369, 20012009.

Malyutina, S., Bobak, M., Kurilovitch, S., et al. (2002). Relation between heavy and binge drinking and all-cause abd cardiovascular mortality in Novosibirsk, Russia: A prospective cohort study. Lancet, 360, 1448-54.

Martikainen, P., Mäki, N., \& Jäntti, M. (2007). The effects of unemployment on mortality following workplace downsizing and workplace closure: A registerbased follow-up study of Finnish men and women during economic boom and recession. American Journal of Epidemiology, 165(9), 1070-1075.

Nemtsov, A.V. (2003). Alcohol consumption in Russia: A viewpoint on monitoring health conditions in the Russian Federation RLMS. Addiction 98, 369-370.

Nilsson, P.M., Nilsson, J., Östergren, P., Berglund, G. (2005). Social mobility, marital status, and mortality risk in an adult life course perspective: The Malmö Preventative Project. Scandinavian Journal of Public Health, 33, 412-423. 
Perlman, F., \& Bobak, M. (2008). Socioeconomic and behavioral determinants of mortality in post-transition Russia: A prospective population study. Annals of Epidemiology, 18(2), 92-100.

Power, C., Matthews. S., \& Manor, O. (1996). Inequalities in self rated health in the 1958 birth cohort: Lifetime social cicumstances or social mobility? BMJ, 313, 449-453.

Riphan, R., \& Zimmerman, K. (2000). The mortality crisis in East Germany. In G.A. Cornia \& R. Paniccia (Eds.), The mortality crisis in transitional economies (pp. 280-302). New York: Oxford University Press.

Rose, D., \& Harrison, E. (2007). The European socio-economic classification: A new social class schema for comparative European research. European Societies, 9(3), 459-490.

Runciman, G.W. (1971). Relative deprivation and social justice: A study of attitudes to social inequality in Twnetieth-Century England. London: Routledge.

Shkolnikov, V., Andreev, E., Leon, D., McKee, M., Meslé. F., \& Vallin, J. (2004a). Mortality Reversal in Russia: The story so far. Hygiea Internationalis, 4(4), 2980 .

Shkolnikov, V., Cornia, G.A., Leon, D., \& Meslé, F. (1998). Causes of the Russian mortality crisis: Evidence and interpretations. World Development, 26(11), 1995-2011.

Shkolnikov, V., McKee, M., \& Leon, D. (2001). Changes in life expectancy in Russia in the mid-1990s. The Lancet, 357, 917-921.

Shkolnikov, V.M., Chervyakov, V.V., McKee, M., Leon, D. (2004b). Russian mortality beyond vital statistics: Effects of social status and behaviours on deaths from circulatory disease and external causes - a case control study of men aged 20-55 years in Udmurtia, 1998-99. Demographic Research, S2(4), 71-104.

Siegrist, J. (2000). Place, social exchange and health: Proposed sociological framework. Social Science \& Medicine, 51, 1283-1293.

Stern, J. (1983). Social mobility and the interpretation of social class mortality differentials. Journal of Social Policy, 12(1), 27-49.

Stillman, S. (2006). Health and nutrition in Eastern Europe and the former Soviet Union during the decade of transition: A review of the literature. Economics and Human Biology, 4, 104-146.

Strully, K.W. (2009). Job loss and health in the U.S. labor market. Demography, 46(2), 221-246.

Treiman, D. (1977). Occupational prestige in comparative perspective. New York: Academic Press.

Vågero, D., \& Kislitsyna, O. (2005). Self-reported heart symptoms are strongly linked to past and present poverty in Russia: Evidence from the 1998 Taganrog interview survey. European Journal of Public Health, 15(4), 418-423.

Walberg, P., McKee, M., Shkolnikov, V., Chenet, L., Leon, D. (1998). Economic change, crime and mortality crisis in Russia: regional analysis. BMJ, 317, 312318. 


\section{Watson, P. (1995). Explaining rising mortality among men in Eastern Europe. Social Science \& Medicine, 41(7), 923-934.}

\section{Appendix A: Summary Statistics}

\begin{tabular}{|c|c|c|c|}
\hline Variable & Exposures & Occurrences & Rate \\
\hline$<40$ years & 37689 & 78 & 0.002 \\
\hline $40-44$ & 8809 & 37 & 0.004 \\
\hline $45-49$ & 8369 & 46 & 0.007 \\
\hline $50-54$ & 6323 & 46 & 0.007 \\
\hline $55-59$ & 5865 & 69 & 0.012 \\
\hline $60+$ & 21390 & 643 & 0.030 \\
\hline men & 37549 & 547 & 0.015 \\
\hline women & 50896 & 387 & 0.008 \\
\hline smoker & 29824 & 334 & 0.011 \\
\hline heavy alcohol cons. & 10076 & 124 & 0.012 \\
\hline non-drinker & 39757 & 558 & 0.140 \\
\hline heart attack diagnosed & 2457 & 103 & 0.042 \\
\hline stroke diagnosed & 1622 & 92 & 0.057 \\
\hline missed work from illness & 4808 & 25 & 0.005 \\
\hline perceives health as poor & 15321 & 547 & 0.036 \\
\hline unemployed & 8632 & 70 & 0.008 \\
\hline routine/manual worker & 14372 & 62 & 0.004 \\
\hline low-mid grade employees & 13630 & 48 & 0.004 \\
\hline intermediate employees/ers & 10562 & 8 & 0.001 \\
\hline salariat & 7250 & 17 & 0.002 \\
\hline caring for someone & 4626 & 6 & 0.001 \\
\hline other reasons not particip. & 29373 & 723 & 0.025 \\
\hline urban residence & 59555 & 566 & 0.010 \\
\hline township & 5370 & 54 & 0.010 \\
\hline rural residence & 23064 & 313 & 0.014 \\
\hline male-headed household & 65140 & 545 & 0.008 \\
\hline female-headed household & 8679 & 82 & 0.010 \\
\hline retired or young head & 14170 & 306 & 0.022 \\
\hline in union & 58039 & 554 & 0.010 \\
\hline not in union & 30053 & 379 & 0.013 \\
\hline incomplete secondary educ & 34987 & 636 & 0.018 \\
\hline complete secondary or more & 37989 & 202 & 0.005 \\
\hline university or institute & 15469 & 96 & 0.006 \\
\hline lowest real household income quartile & 21103 & 251 & 0.012 \\
\hline low-mid real household income quartile & 21079 & 311 & 0.015 \\
\hline mid-high real household income quartile & 21089 & 203 & 0.010 \\
\hline highest real household income quartile & 21088 & 144 & 0.007 \\
\hline relative wealth: lowest 3 steps & 40962 & 561 & 0.014 \\
\hline relative wealth: mid 3 steps & 43572 & 302 & 0.007 \\
\hline relative wealth: highest 3 steps & 2413 & 11 & 0.005 \\
\hline DSM: subjective wealth distribution & 10897 & 155 & 0.014 \\
\hline no DSM & 77548 & 779 & 0.010 \\
\hline ever experienced unemployment & 42427 & 535 & 0.013 \\
\hline never & 46018 & 399 & 0.009 \\
\hline ever experienced DSM & 32234 & 368 & 0.011 \\
\hline never & 56211 & 566 & 0.010 \\
\hline
\end{tabular}


Appendix B. Reduced models

Cox Proportional Hazard Risks of Death in Russia, 1994-2005

\begin{tabular}{lll}
\hline \multicolumn{3}{c}{ Relative Risks of Age and Education Model } \\
\hline \hline$<40$ years & \multicolumn{1}{c}{ Men } & Women \\
& 1 & 1 \\
$40-44$ & $2.02^{\star \star \star}$ & 1.93 \\
& $(0.44)$ & $(0.94)$ \\
$45-49$ & $3.73^{\star \star \star}$ & $3.10^{\star \star \star}$ \\
& $(0.70)$ & $(1.28)$ \\
$50-54$ & $3.39^{\star \star \star}$ & $5.16^{\star \star \star}$ \\
& $(0.73)$ & $(1.99)$ \\
$55-59$ & $5.59^{\star \star \star}$ & $6.10^{\star \star \star}$ \\
& $(1.04)$ & $(2.21)$ \\
$60+$ & $10.98^{\star \star \star}$ & $22.39^{\star \star \star}$ \\
incomplete secondary educ & $(1.56)$ & $(6.33)$ \\
& 1 & 1 \\
complete secondary or more & $0.83^{\star}$ & $0.48^{\star \star \star}$ \\
& $(0.08)$ & $(0.06)$ \\
university or institute & $0.63^{\star \star \star}$ & $0.38^{\star \star \star}$ \\
\# of subjects & $(0.08)$ & $(0.08)$ \\
\# of deaths & 8938 & 10830 \\
Time at risk & 547 & 387 \\
Log Pseudolikelihood & 37549 & 50896 \\
Prob > chi2 & -4275.9 & -3029.4 \\
Wald chi2 (7) & 0.0000 & 0.0000 \\
& 430.41 & 378.84
\end{tabular}




\begin{tabular}{lll}
\hline \hline & \multicolumn{1}{c}{ Men } & Women \\
\hline$<40$ years & 1 & 1 \\
& $2.02^{\star \star \star}$ & 2.01 \\
$40-44$ & $(0.44)$ & $(0.99)$ \\
& $3.73^{\star \star \star}$ & $3.36^{\star \star \star}$ \\
$45-49$ & $(0.70)$ & $(1.39)$ \\
& $3.43^{\star \star \star}$ & $6.02^{\star \star \star}$ \\
$50-54$ & $(0.73)$ & $(2.33)$ \\
& $5.94^{\star \star \star}$ & $8.30^{\star \star \star}$ \\
$55-59$ & $(1.10)$ & $(3.02)$ \\
& $12.85^{\star \star \star}$ & $39.08^{\star \star \star}$ \\
$60+$ & $(1.77)$ & $(10.74)$ \\
\hline & $1.33^{\star \star \star}$ & $1.70^{\star \star}$ \\
current smoker & $(0.11)$ & $(0.38)$ \\
\hline \# of subjects & 8938 & 10830 \\
\# of deaths & 547 & 387 \\
Time at risk & 37549 & 50896 \\
Log Pseudolikelihood & -4277.2 & -3052.1 \\
Prob > chi2 & 0.0000 & 0.0000 \\
Wald chi2 (6) & 440.71 & 345.97
\end{tabular}

